\title{
E-services: The Next Wave of Internet-Based Applications
}

\author{
Alejandro Buchmann \\ Darmstadt University of Technology \\ Wilhelminenstr. 7 \\ 64283 Darmstadt, Germany \\ buchmann@informatik.tu-darmstadt.de
}

E-services (or their close relatives, Web-services) are defined as self-contained, modular applications that can be described, published, located, and invoked over a network. E-services enable an application developer who has a certain need, to fulfill it by using an appropriate e-service that has been published, for example, on the Web, rather than developing the code from scratch.

Simple e-services, such as delivery of business information (airline schedules, stock quotes, status of an ongoing auction) and basic transactional services (hotel reservations, single site purchases, bidding in an auction) have been available for some time via web browser interfaces. Most of these simple e-services represent the first generation of $\mathrm{B} 2 \mathrm{C}$ e-commerce applications.

$\mathrm{B} 2 \mathrm{~B}$ process integration requires complex e-services that provide support for work ows and process integration among different businesses. Complex e-services are state-preserving and must be composable in the sense that services provided by independent organizations can be combined to provide an added value. It is particularly important for these services to be properly described and that the parties involved in providing and consuming the service can negotiate the terms and conditions of use.

This panel will address the challenges faced by e-service providers. It will present the results of a companion panel on the technical platforms for e-services held as part of the Middleware 2001 Conference and will then concentrate on the challenges for value-added services: standardization, composition, integration, context specification, brokering, reliability, security and privacy, transactions, pricing, accounting, and contracting. These are the challenges that must be addressed for the vision of value-added e-services to become a reality. 